\title{
Article
}

\section{A comparison of pharmacy student attainment, progression, and perceptions using team- and problem-based learning: Experiences from Wolverhampton School of Pharmacy, UK}

Rutter, Paul and Nation, Leanne Marie

Available at http://clok.uclan.ac.uk/14211/

Rutter, Paul ORCID: 0000-0003-4106-1515 and Nation, Leanne Marie (2015) A comparison of pharmacy student attainment, progression, and perceptions using team- and problem-based learning: Experiences from Wolverhampton School of Pharmacy, UK. Currents in Pharmacy Teaching and Learning, 7 (6). pp. 884-891. ISSN 1877-1297

It is advisable to refer to the publisher's version if you intend to cite from the work. http://dx.doi.org/10.1016/j.cptl.2015.08.019

For more information about UCLan's research in this area go to

http://www.uclan.ac.uk/researchgroups/ and search for < name of research Group>.

For information about Research generally at UCLan please go to http://www.uclan.ac.uk/research/

All outputs in CLoK are protected by Intellectual Property Rights law, including Copyright law. Copyright, IPR and Moral Rights for the works on this site are retained by the individual authors and/or other copyright owners. Terms and conditions for use of this material are defined in the policies page. 


\section{AUTHOR QUERY FORM}

\begin{tabular}{|l|l|l|}
\hline & & Please e-mail your responses and any corrections to: \\
\hline ELSEVIER & Journal: CPTL & \\
\hline
\end{tabular}

Dear Author,

Please check your proof carefully and mark all corrections at the appropriate place in the proof (e.g., by using on-screen annotation in the PDF file) or compile them in a separate list. Note: if you opt to annotate the file with software other than Adobe Reader then please also highlight the appropriate place in the PDF file. To ensure fast publication of your paper please return your corrections within 48 hours.

For correction or revision of any artwork, please consult http://www.elsevier.com/artworkinstructions.

Any queries or remarks that have arisen during the processing of your manuscript are listed below and highlighted by flags in the proof. Click on the $\underline{Q}$ link to go to the location in the proof.

Your article is registered as a regular item and is being processed for inclusion in a regular issue of the journal. If this is NOT correct and your article belongs to a Special Issue/Collection please contact b.ramakrishna@elsevier.com immediately prior to returning your corrections.

\begin{tabular}{|c|l|}
\hline $\begin{array}{c}\text { Location in } \\
\text { article }\end{array}$ & $\begin{array}{c}\text { Query / Remark: click on the Q link to go } \\
\text { Please insert your reply or correction at the corresponding line in the proof }\end{array}$ \\
\hline$\underline{\text { Q1 }}$ & $\begin{array}{l}\text { Please confirm that given names and surnames have been identified correctly and are presented in the desired order. } \\
\text { Quthor: } \\
\text { If there are any drug dosages in your article, please verify them and indicate that you have done so by initialing this } \\
\text { query. } \\
\text { Please review and confirm the accuracy and completeness of any affiliations. }\end{array}$ \\
$\underline{\text { Q3 }}$ & $\begin{array}{l}\text { Reference(s) given here were noted in the reference list but are missing from the text - please position each reference in the } \\
\text { text or delete it from the list. } \\
\text { Please check the address for the corresponding author that has been added here, and correct if necessary. }\end{array}$ \\
$\underline{\text { Q5 }}$ & $\begin{array}{l}\text { If there are fewer than seven authors, please supply all their names; if there are seven or more authors, supply the first } \\
\text { three authors' names, followed by 'et al.' }\end{array}$ \\
\hline
\end{tabular}

Thank you for your assistance.

Please check this box or indicate your approval

if you have no corrections to make to the PDF file 


\title{
A comparison of pharmacy student attainment, progression, and perceptions using team- and problem-based learning: Experiences from Wolverhampton School of Pharmacy, UK
}

\author{
Leanne Marie Nation, MSc ${ }^{*}$, Paul Rutter, PhD \\ School of Pharmacy, University of Wolverhampton, West Midlands, UK
}

\begin{abstract}
Objective: To compare pharmacy student attainment, progression, and perception of team-based (TBL) and problem-based learning (PBL) in comparison to more traditional didactic teaching methods.

Design: Student attainment and progression were established through comparison of examination data before and after TBL implementation and for the three teaching methodologies. Student perceptions of TBL and PBL were sought via a questionnaire and focus group. Assessment: Summative examination performance was used to assess the effect of TBL implementation. Student attainment and progression increased after TBL implementation (attainment grade score: pre-TBL 7.7 vs. 11.19 post-TBL; $p=0.01$ and progression: $89 \%$ vs. $92 \% ; p=0.574)$. Summative examination performance was also used to assess the effect of three teaching methodologies in the same cohort. Student attainment was higher with TBL compared with PBL (grade score: 11.19 vs. 8.73; $p \leq 0.001$ ) and slightly but not significantly worse than those seen with traditional didactic teaching (grade score: 11.19 vs. $11.83 ; p=0.355$ ). Student progression was the highest with traditional teaching, then TBL, and finally PBL ( $96 \%$ vs. $92 \%$ vs. $88 \% ; p=0.224)$. Student perceptions favored TBL compared with PBL but traditional teaching methods were favored over both TBL and PBL.

Conclusion: The study shows that student attainment and progression were better using TBL compared with PBL, although traditional approaches to teaching saw comparable attainment and progression to TBL. Student perceptions favored traditional teaching more than TBL, which was more liked than PBL.
\end{abstract}

(C) 2015 Published by Elsevier Inc.

Keywords: Team-based learning; Problem-based learning; Student perception

\section{Introduction}

Active learning with new educational methods, such as problem-based learning (PBL) and team-based learning (TBL) (Fig. defines these teaching methodologies), is becoming established in health care education. Health

* Corresponding author: Leanne Marie Nation, MSc, School of Pharmacy, University of Wolverhampton, Wulfruna Street, Wolverhampton, West Midlands WV11SB, UK.

E-mail: Leanne.nation@wlv.ac.uk professional education programs, in particular medical education, have been at the forefront of implementing and using these new methods of learning. ${ }^{1,2}$

This is, in part, due to medical regulatory bodies raising concerns that "traditional" medical education-didactic teaching, would not meet the needs of current and future doctors. ${ }^{1}$ The use of PBL began in undergraduate medical education at the end of the 1960s, and McMaster University School of Medicine in Canada was the first institution to adopt a curriculum delivered through the PBL approach. ${ }^{1}$ Subsequently, medical schools across the globe introduced 
100 PBL, for example, Beer Sheva (Israel), Maastricht (the 101 Netherlands), Newcastle (Australia), and Albuquerque 102 (US). ${ }^{1}$ TBL is a more recent teaching methodology, which 103 was developed by Larry Michaelson in the late 1970s in 104 business education. ${ }^{5}$ Subsequently, it has been adopted in 105 health professional education, and is now commonly 106 employed in medical education, and used to teach topics 107 such as evidence-based medicine, clinical experiences, and 108 clerkships. $^{1}$

109 The benefits of PBL and TBL in medical education have 110 been shown, but the picture in pharmacy education is less 111 clear. PBL in pharmacy education was first described in the 112 early 1980s, where PBL was used to teach problem solving 113 skills, but it was not until the mid to late 1990s that 114 widespread use was reported in US pharmacy schools. ${ }^{6}$

The use of TBL in pharmacy education was first reported by Letassy et al. ${ }^{7}$ Like PBL, the adoption of TBL in a number of pharmacy schools has since been reported. ${ }^{8,9}$ The use of these methods in undergraduate pharmacy education is likely to grow, given that accreditation bodies such as the Accreditation Council for Pharmacy Education and the Australian Pharmacy Council advocate their use. $^{10,11}$

The effect of PBL and TBL on student attainment (examination performance) and progression (examination a show mixed outcomes. For example, Raman-Wilms ${ }^{12}$ 127 and Romero et al. ${ }^{13}$ both found that PBL increased student increase in student attainment. TBL outcomes appear to be 158 more positive. Letassy et al. ${ }^{7}$ and Conway et al. ${ }^{16}$ found that student progression rates increased. Both authors reported that there was a lower failure rate after TBL implementation compared with historical pre-TBL data, which used a more traditional approach. Student perception also seems to favor TBL over PBL. ${ }^{12,17}$

\section{Rationale and objectives}

Given the emergence of these teaching methods within pharmacy education, and the generally positive outcomes associated with them, the pharmacy course committee at the University of Wolverhampton decided to pilot the use of PBL and TBL teaching in the third year of the program (in the UK, students study for four years at the university before undertaking a one-year clinical internship prior to registration) alongside traditional teaching methodologies. PBL was used to deliver a therapeutics module that covered respiratory, gastrointestinal, and endocrine conditions; TBL was used to teach a differential diagnosis and prescribing module. For comparison purposes, relating to student attainment, a module (that covered pharmaceutical biotechnology) taught using traditional didactic methods was included. The aim of the study was to compare TBL, PBL, and traditional didactic methods in student attainment, 
184 progression, and perception at the University of Wolver185 hampton, School of Pharmacy.

\section{Materials and methods}

A mixed-method approach was used. Exam data were analyzed to gauge attainment and progression and a student survey and focus group schedule were performed to investigate student perception toward the introduction of PBL and TBL.

\section{Attainment data}

Student performance was assessed via summative marks gained at the end of each module. The University of Wolverhampton employs a grade point score system (GPA), where zero is the lowest score and 16 is the highest achievable score; a score of five or greater is a pass. Data were reviewed in two ways.

Firstly

- Before and after TBL implementation: Historical exam result data, for the academic year 2010/2011 (taught in a traditional manner), were compared to exam results from 2012/2013 that used the TBL approach. No data for 2011/2012 were available as the module was not taught due to a course restructure. Examination scores were entered into SPSS (version 20 ), and then analyzed using descriptive statistics and statistically using an independent $t$-test. Exams sat by both pre- and post-TBL cohorts followed the same assessment pattern. Standard TBL methodology was employed (irat/grat/tapps) but counted only as formative marking and not summative. This allowed comparison of summative performance as both cohorts sat the same summative examination diet.

And secondly

- TBL vs. PBL (vs. traditional): Exam data for the academic year 2012/2013 were compared from the three respective modules. Examination scores were entered into SPSS (version 20), and then analyzed using descriptive statistics and statistically using oneway ANOVA and post hoc analysis Bonferroni test.

\section{Progression data}

Final student scores for each respective module were acquired through standard university systems that allowed 4 tracking of individual progression. Each of the three respective modules had varying assessment patterns but ultimately had a percentage mark, which was used as the 7 basis for establishing progression. Progression data were entered into SPSS (version 20), and then analyzed using descriptive statistics and statistically using Fisher's exact test to allow comparisons between modules using different 240 teaching methodologies.

Survey

The survey was developed to gather student perception 245 of PBL and TBL compared to more traditional didactic 246 teaching. It was administered to all third-year $(n=75) 247$ students after year three teaching had finished. Students 248 were provided with the details of the study and an 249 information sheet. Prior to completing the survey, students gave written consent.

The survey contained 30 items, of which 27 were fivepoint Likert scale questions that used a strongly agree to strongly disagree scale; three questions were free text responses. The survey consisted of four sections: section A established basic demographic information; sections B (10 questions) and $\mathrm{C}$ (nine questions) looked at student perception of PBL and TBL; and section D (11 questions) aimed to establish their overall view of PBL and TBL in comparison to traditional teaching methods.

The survey was assessed for reliability and validity. Cronbach's alpha was used to test the reliability and the survey was shown to be reliable (Cronbach's $\alpha=0.899$ ). A face validity check was performed; the questions were checked for ease of reading as well as the overall layout, and were shown to be valid.

The survey was then piloted on 10 randomly selected fourth-year students. Following the pilot, minor amendments to three of the questions were made to aid clarity. No other changes were made.

Likert data were entered into SPSS (version 20) and analyzed by aggregating positive and negative responses to produce percentage responses. Data were then statistically analyzed using the paired $t$-test to compare student's responses to survey sections $\mathrm{B}$ (PBL) and $\mathrm{C}$ (TBL). Responses to the open-ended questions were analyzed thematically by the lead author L.N. and verified by P.R., and findings used as a basis for constructing the focus group schedule questions.

\section{Focus group}

For the focus group, all third-year students were invited via e-mail to participate in a focus group. Students were provided with the details of the focus group and its purpose, and written consent was gained prior to the start of the focus group.

The focus group schedule explored how students approached the preparatory work for PBL and TBL, their attitude toward delivery, and asked for their general thoughts on PBL and TBL. No specific questions were posed on traditional teaching methods. A face validity check was performed on the focus group schedule by two experienced researchers, and found to be valid. No changes were made to the focus group schedule. 
296 Six students volunteered to attend a focus group; as a 297 consequence one focus group $(n=6)$ was conducted at the 298 University of Wolverhampton by L.N., who acted as the 299 moderator, along with a second assistant moderator to 300 facilitate data capture. The focus group was audio recorded 301 and then transcribed verbatim. The moderator did not 302 deviate from the focus group schedule.

303 For data analysis, each student was given a student code 304 to ensure anonymity. The transcript was repeatedly listened 305 to until the researcher was familiar with the content and then 306 transcribed verbatim. The data were analyzed using constant 307 comparison analysis to derive emergent themes. Ethical 308 approval was gained from the behavioral science ethics 309 committee at the University of Wolverhampton.

\section{Evaluation and assessment}

\section{Student attainment data}

Student attainment and progression before and after TBL implementation are shown in Table 1. Students achieved a higher mean GPA score after TBL (11.19) implementation compared with before TBL (7.70) implementation; this difference was significant (independent $t$-test, $p=0.01$ ). Progression rates were also higher after TBL implementation (92\%) compared with before TBL (89\%), although this result did not reach significance (Fisher's exact test, $p=0.574$ ).

The average year end grade point average (GPA) scores achieved for both cohorts (2010/11 and 2012/13) were compared to see if changes in GPA scores were associated with the TBL teaching methodology rather than cohort differences in academic ability. For 2010/11, the average year end GPA score was 9.14 (compared with 7.70 for the specific module differential diagnosis and prescribing) and in 2012/13, the year GPA score was 10.06 (compared with 11.19). This seems to suggest that increased attainment was due to TBL and not cohort differences.

Student attainment and progression data for the three modules studied in year three of the program showed that students achieved the highest mean GPA score with traditional teaching methods (11.83), followed by TBL (11.19) and then PBL (8.73); this difference was significant (oneway ANOVA, $p<0.001)$. Further post hoc analysis using the Bonferroni test showed a significant difference between TBL and PBL attainment $(p<0.001)$ and similarly

Table 1

Student attainment (average grade point score) and progression (\%) data before and after TBL implementation

\begin{tabular}{lclll}
\hline & Attainment & $p$ Value & Progression & $p$ Value \\
\hline Pre-TBL & 7.70 & - & 89.1 & - \\
Post-TBL & 11.19 & $0.01^{\mathrm{a}}$ & 92.0 & $0.574^{\mathrm{b}}$ \\
\hline
\end{tabular}

TBL, team-based learning.

${ }^{\text {a }}$ Independent $t$-test.

${ }^{\mathrm{b}}$ Fisher's exact test. between traditional methods and PBL $(p<0.001)$. No significant difference was seen between TBL and traditional teaching $(p=0.355)$. Progression rates were the highest in the traditional module $(96.0 \%)$, followed by TBL $(92.0 \%)$ and then PBL (88.0\%), although these did not reach significance (Fisher's exact test, $p=0.224$ ).

\section{Survey data}

A response rate of $57.3 \%(n=43)$ was obtained. In all, 19 respondents $(44.2 \%)$ were females and $24(55.8 \%)$ were males. Student perception on preparation for PBL and TBL sessions is shown in Table 2. More students enjoyed completing TBL work compared with PBL and also felt that TBL preparatory work increased their understanding of module material more than PBL, although these findings did not reach statistical significance.

Student perception of their "engagement" during workshops is shown in Table 3. All (100\%) students agreed that the preparatory multiple-choice question (MCQ) test used in TBL gave them a better understanding of module material; this is compared with 55.8\% in PBL. Most students agreed that discussing (84\%) and completing (84\%) the MCQs within their TBL teams during the workshop was beneficial to their learning. In comparison, $60.4 \%$ agreed that the PBL question and answer (Q\&A) session for their group's presentation was beneficial to their learning and $58.1 \%$ agreed that taking part in other group's Q\&A sessions gave them a better understanding of the module material. Approximately a third of the students disagreed that listening to other groups PBL presentations helped their understanding.

Table 4 reports student perception on the effectiveness of the two teaching methods, PBL and TBL. More students $(60.5 \%)$ agreed that TBL was more effective than lectures, compared with $44.2 \%$ agreement for PBL; this did not reach significance (paired $t$-test, $p=0.68$ ). Similarly, more students $(55.8 \%)$ agreed that TBL was a better way to deliver material than lecturing, which was higher than that of PBL (35\%); this difference was significant (paired t-test, $p=0.002$ ).

General student perception of the three teaching methodologies is shown in Table 5. TBL (60.5\%) and traditional methods $(60.5 \%)$ were equally enjoyed by students, which were higher than that of PBL (51.1\%). Not surprisingly then, the students' least preferred learning methodology was PBL. There is similar agreement with PBL, TBL, and traditional methods of teaching regarding the methods students feel they learn best. Traditional methods $(60.5 \%)$ and TBL $(58.1 \%)$ were the preferred method of teaching, compared with $39.5 \%$ preferring PBL.

Open-ended questions asking for student perception on their experiences revealed a degree of commonality between their PBL and TBL experiences. For PBL, four themes were identified: student engagement; understanding and learning; quality of presentations; and learning style. For TBL, three themes were identified: team working, understanding and learning, and learning style. 
408 Table 2

409 Student perception of PBL and TBL in relation to preparatory work $(n=43)$

414 I always complete the preparatory work set by the tutor

415 for a PBL/TBL session

416 I enjoy completing the preparatory work for a PBL session

417 in a group/TBL session individually

418 I have a better understanding of the module material by

419 doing the PBL preparatory group work/TBL individual preparatory

425 Table 3

426 Student perception of PBL and TBL workshops $(n=43)$ directed reading work

PBL, problem-based learning; TBL, team-based learning.

436 I have a better understanding of the module material by taking part in the question and answer 437 session for the other groups' presentations

\begin{tabular}{lllllll} 
PBL & \multicolumn{7}{l}{ TBL } \\
\cline { 1 - 3 } \cline { 5 - 6 } $\begin{array}{lllllll}\text { Agree, } \\
\%(n)\end{array}$ & $\begin{array}{l}\text { Neutral, } \\
\%(n)\end{array}$ & $\begin{array}{l}\text { Disagree, } \\
\%(n)\end{array}$ & $\begin{array}{l}\text { Agree, } \\
\%(n)\end{array}$ & $\begin{array}{l}\text { Neutral, } \\
\%(n)\end{array}$ & $\begin{array}{l}\text { Disagree, } \\
\%(n)\end{array}$ \\
\hline $95.4(41)$ & $2.3(1)$ & $2.3(1)$ & $97.7(42)$ & $2.3(1)$ & 0 \\
$57.1(25)$ & $31.0(13)$ & $11.9(5)$ & $69.7(30)$ & $30.2(13)$ & 0 \\
$83.4(36)$ & $9.5(4)$ & $7.1(3)$ & $93.1(40)$ & $7.0(3)$ & 0
\end{tabular}

TBL workshops

Characteristic

Agree, Neutral, $\quad$ Disagree,

PBL workshops

I have a better understanding of the module material by delivering the pre-prepared group $\%(n)$ $\%(n)$ $\%(n)$

have a better understanding of the module material by taking part in the question and answer session on the presentation delivered by my group

I have a better understanding of the module material by listening to other groups deliver their pre-prepared work to the class

$55.8(24) \quad 25.6(11) \quad 18.6(8)$

$60.4(26) \quad 20.9(9) \quad 18.6(8)$

I have a better understanding of the module material by doing the individual preparatory multiple-choice questions (MCQs)

441 I have a better understanding of the module material by discussing the MCQs in teams

442 in the workshop

443 I have a better understanding of the module material by completing the MCQs in teams 444 in the workshop

PBL, problem-based learning; TBL, team-based learning.

Student perception on the effectiveness of PBL and TBL $(n=43)$

$\begin{array}{lll}100.0(43) & 0 & 0 \\ 83.7(36) & 11.6(5) & 4.7(2) \\ 83.7(36) & 11.6(5) & 4.7(2)\end{array}$

\begin{tabular}{|c|c|c|c|c|c|c|c|}
\hline & \multicolumn{3}{|l|}{ PBL } & \multicolumn{3}{|l|}{ TBL } & \multirow[b]{2}{*}{$p$ Value } \\
\hline & $\begin{array}{l}\text { Agree, } \\
\%(n)\end{array}$ & $\begin{array}{l}\text { Neutral, } \\
\%(n)\end{array}$ & $\begin{array}{l}\text { Disagree, } \\
\%(n)\end{array}$ & $\begin{array}{l}\text { Agree, } \\
\%(n)\end{array}$ & $\begin{array}{l}\text { Neutral, } \\
\%(n)\end{array}$ & $\begin{array}{l}\text { Disagree, } \\
\%(n)\end{array}$ & \\
\hline $\begin{array}{l}\mathrm{PBL} / \mathrm{TBL} \text { is a more effective way of learning } \\
\text { than lecturing }\end{array}$ & 44.2 (19) & $32.6(14)$ & $23.3(10)$ & $60.5(26)$ & $18.6(8)$ & $21(9)$ & $0.68^{\mathrm{a}}$ \\
\hline $\begin{array}{l}\mathrm{PBL} / \mathrm{TBL} \text { is a better method of delivery } \\
\text { of the module material than lecturing }\end{array}$ & 34.9 (15) & $30.2(13)$ & 34.9 (15) & $55.8(24)$ & 20.9 (9) & $23.3(10)$ & $0.002^{\mathrm{a}}$ \\
\hline $\begin{array}{l}\text { PBL, problem-based learning; TBL, team-based learni } \\
{ }^{\text {a }} \text { Paired } t \text {-test. }\end{array}$ & & & & & & & \\
\hline
\end{tabular}




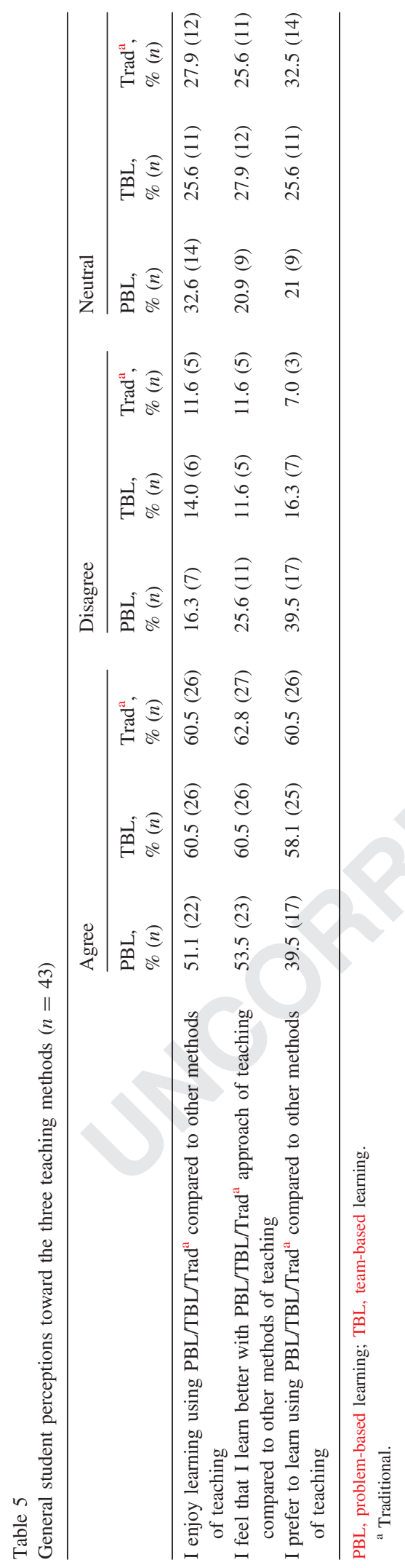

Understanding and learning styles were common emergent themes in PBL and TBL; students liked being able to research a topic in depth for PBL and TBL; but in PBL, some found it difficult when they came across material they could not understand. Students found TBL to be a useful teaching method, as it allowed them to research the topic and then use the MCQ test to test their own knowledge. Secondly regarding learning style, students generally preferred traditional teaching to PBL, but would like to see PBL continue if supplemented with additional lectures. Similarly, students preferred traditional lectures compared with TBL.

The two themes attributed to PBL only were student 588 engagement and quality of presentations. With student 589 engagement students enjoyed working as part of a group, 590 but found it difficult when some group members did not 591 contribute to the task. Secondly, students felt the material 592 presented to them by other students was of poor quality and 593 not appropriate for revision purposes. The third theme 594 attributed to TBL only was team working; students felt it 595 was beneficial working within a team to discuss the 596 material, but most students highlighted that not everyone 597 contributed to the team discussions.

Focus group

Six students took part in a single focus group. Student's 602 perception was broadly categorized into positive and 603 negative attributes.

\section{Positive attributes}

Students highlighted the positive aspects of PBL and TBL, in particular working with new people, improving their team working skills, and taking responsibility for selfdirected work. Students also valued the feedback provided in both PBL and TBL sessions and found this useful to highlight gaps in their knowledge. Students preferred TBL, with students seeing the benefit of participating in TBL team discussions, which allowed them to learn from each other and helped to increase their confidence.

I valued the team discussions (in TBL), they can give you different perspectives of the right answer and explain it better-FGP3.

Having the individual and group test scores available in the TBL session was seen as particularly beneficial, as this provided immediate feedback. The transparent nature of knowing each others' scores created competitiveness between students to work harder.

Negative attributes

Students did not highlight any disadvantages to TBL but did voice concern over PBL, in particular, group members not equally contributing to the given task, for example 
632 preparing a presentation. Adopting this approach led to a 633 lack of understanding toward specific topic areas.

It's easier to split it all up (work), which is a disadvantage, I knew my slide really well, but I did not understand the other slides-FGP4.

Opinions toward PBL presentations were negative; students spoke of group members not attending to present their work, which resulted in a lack of quality in the information presented, as other students had to present the absent student's work.

\section{Discussion}

This study has shown that PBL was associated with the poorest attainment and progression and was the least preferred by students. Attainment and progression improved following implementation of TBL, and were comparable to those by traditional teaching methods in the comparator module. Furthermore, student attainment was significantly higher after TBL implementation when compared with before TBL implementation. These findings echo those reported both in pharmacy ${ }^{7,18-21}$ and medical education, ${ }^{22-}$

also seem consistent with 658 the majority of the pharmacy literature, which show that 659 PBL has no difference in student attainment. ${ }^{13-15}$ This has 660 also been shown in the medical literature. ${ }^{27,28}$

661 Students clearly preferred TBL over PBL, which again 662 mirrors the findings of other studies both in pharmacy ${ }^{19,29}$ 663 and medical education. ${ }^{22-24,30,31}$ With TBL, students liked 664 doing the preparatory work individually, as they were 665 responsible for their own learning, but valued the group 666 discussion as it allowed them to better understand the 667 material content. Both of these are reflective of other 668 studies. $^{18,21}$

669 Overall, student perception similarly favored traditional 670 teaching and TBL, and both were generally preferred to 671 PBL. This was somewhat expected with traditional teach672 ing, more so than with TBL, given that students had been 673 taught in this manner for the previous two years and were 674 familiar with this method of learning. Newer approaches 675 such as PBL and TBL place greater emphasis on students 676 acquiring knowledge rather than being imparted this knowl677 edge through traditional teaching methods. This shift in 678 learning, along with unfamiliarity of the new methods, may 679 go some way in explaining the differences in the findings 680 with PBL. Additionally, this preference may account for 681 differences in attainment; liking seems to be linked to 682 performance and it may not be the instructional method 683 per se that accounts for those differences. Further work is 684 needed to explore this. Student attainment and progression 685 using TBL were very similar to those by traditional 686 methods, which suggest that TBL will be an important 687 instructional method to be used with future cohorts.
An unexpected finding from the results of TBL was the 688 emergence of competitiveness. Students liked having a 689 score for their individual MCQs (iRAT); they found that 690 the competitiveness that arose from the publication of these 691 results gave them the drive to work harder. This "compet- 692 itive" dimension to TBL does not appear to have been 693 reported in other pharmacy TBL papers. At the University 694 of Wolverhampton, students normally receive their results 695 individually, and they are not shared with other students. 696 With TBL, students knew each other's marks (students 697 agreed to marks being shared); this transparency of scores in 698 a public forum allowed students, for the first time, to 699 benchmark themselves against each other, and this seems to 700 have given students the drive and motivation to perform 701 better. This finding requires further investigation to better 702 understand the competitiveness nature of TBL and how best 703 this can be harnessed to drive student learning.

Students did not like or perform particularly well using PBL. Students found it undesirable having to rely on peers and other PBL groups to gather, present, and rely on this information. These findings might, in part, be explained by students stating that they felt underprepared to present assigned topics. Other pharmacy educators have reported similar student engagement issues. ${ }^{12,17}$ In contrast, medical education seems to report more positive accounts of students' preparedness and engagement. ${ }^{27,32}$ These differences, from a UK perspective, between pharmacy and medical students might be explained by the "type" of student each discipline attracts. In the UK, medical schools are highly oversubscribed, allowing them to selectively recruit the most able and committed students through rigorous selection processes. This is not the case in pharmacy, where recent expansion in the number of schools of pharmacy has led to pharmacy programs taking students whose first degree choice may not be pharmacy. ${ }^{33}$

This may affect how students want to be taught; PBL is a more self-driven teaching method compared with TBL (which is more structured) and traditional lecture-type delivery and the latter two methodologies require less self-learning. Self-determination theory, as reported by Albanese, highlights two types of motivating conditions: controlled and autonomous. ${ }^{34}$ In autonomous motivators, subject interest drives learning; in those students where pharmacy may not be the first choice, there is the potential for less motivation and possibly less success with PBL. Compounding our findings may also be the concept of situational context, reported as being important with PBL. ${ }^{32}$ UK undergraduate pharmacy students have limited exposure to the workplace, which is in stark contrast with medical students.

The study does have limitations. Firstly, the attainment data before and after TBL implementation were from two different student cohorts. Therefore, the results could be due to differences in student cohorts rather than the instructional method. The average GPA score across the year for the preTBL-implementation cohort was 9.14, compared with the 
744 GPA score for the module in the study of 7.7 ; students 745 performed below the average year GPA score. The average 746 GPA score across the year for the post-TBL-implementation 747 cohort was 10.06, compared with the GPA score for the 748 module in the study of 11.19 ; students performed better than 749 the average year GPA score. Given that the content did not 750 change, improvement in attainment is likely due to the TBL 751 methodology rather than cohort differences. Secondly, some 752 students may naturally perform better in one area of the 753 program than another (the three modules covered different 754 aspects of the program), despite the teaching method used. 755 We acknowledge this problem, but in the study design this 756 could not be mitigated against. It is possible that students 757 found content from one module easier than another and 758 might account for some of the differences seen in attainment 759 and progression. However, student feedback did support the 760 notion that PBL was the least preferred and was therefore 761 likely to influence their performance.

\section{Conclusion}

The study results indicate that students favor the use of TBL and traditional learning methods compared with PBL. Following implementation of TBL in a differential diagnosis and prescribing module, student attainment improved significantly.

\section{Uncited references}

3,4 .

\section{Acknowledgments}

The authors acknowledge Dr. Paul Wilson, University of Wolverhampton, for his assistance with the statistical analysis. The authors also acknowledge Dr. Elizabeth Mills and Ms Maria Allinson, Keele university, for their assistance with the study design.

\section{References}

1. Johnson SM, Finucane PM. The emergence of problem-based learning in medical education. J Eval Clin Pract. 2000;6(3): 281-291.

2. Searle NS, Haidet P, Kelly PA, et al. Team learning in medical education: initial experiences at ten institutions. Acad Med. 2003;78(suppl 10):S55-S58.

3. Wood DF. ABC of learning and teaching in medicine. Problem based learning. Br Med J. 2003;326(7384):328-330.

4. Farland MZ, Sicat BL, Franks AS, et al. Best practices for implementing team-based learning in pharmacy education. Am J Pharm Educ. 2013;77(8): Article 177.

5. Michaelsen LK, Parmelee DX, McMahon KK, et al. Teambased learning for health professions education. Sterling, VA: Stylus; 2008.

6. Cisneros RM, Salisbury-Glennon JD, Anderson-Harper HM. Status of problem-based learning research in pharmacy education: a call for future research. Am J Pharm Educ. 2002;66(1):19-26.

7. Letassy NA, Fugate SE, Medina MS, et al. Using team-based learning in an endocrine module taught across two campuses. Am J Pharm Educ. 2008;72(5): Article 103.

8. Ofstad W, Brunner LJ. Team-based learning in pharmacy education. Am J Pharm Educ. 2013;77(4): Article 70.

9. Allen RE, Copeland J, Franks AS, et al. Team-based learning in US colleges and schools of pharmacy. Am J Pharm Educ 2013;77(6): Article 115.

10. Accreditation for Pharmacy Education. Accreditation standards and guidelines for the professional program in pharmacy leading to the Doctor of Pharmacy Degree. Available at: 〈https://www.acpe-accredit.org/pdf/FinalS2007Guidelines2.0.pdf〉. Accessed August 2, 2015.

11. Australian Pharmacy Council Ltd. Accreditation standards for pharmacy education programs in Australia and New Zealand. Available at: 〈http://pharmacycouncil.org.au/content/assets/files/ Publications/Accreditation $\% 20$ Standards $\% 20$ for $\% 20$ Pharmacy $\%$ 20Degree\%20Programs\%202014.pdf $\rangle$. Accessed August 2, 2015.

12. Raman-Wilms L. Innovative enabling strategies in selfdirected, problem-based therapeutics: enhancing student preparedness for pharmaceutical care practice. Am J Pharm Educ. 2001;65(1):56-64.

13. Romero RM, Eriksen SP, Haworth IS. Quantitative assessment of assisted problem-based learning in a pharmaceutics course Am J Pharm Educ. 2010;74(4): Article 66.

14. Ross LA, Crabtree BL, Theilman GD, et al. Implementation and refinement of a problem-based learning model: a ten year experience. Am J Pharm Educ. 2007;71(1): Article 17.

15. Romero RM, Eriksen SP, Haworth IS. A decade of teaching pharmaceutics using case studies and problem-based learning. Am J Pharm Educ. 2004;68(2): Article 31.

16. Conway SE, Johnson JL, Ripley TL. Integration of team-based learning strategies into a cardiovascular module. Am J Pharm Educ. 2010;74(2): Article 35.

17. Bratt AM. A large group hybrid lecture and problem-based learning approach to teach central nervous system pharmacology within the third year of an integrated masters level pharmacy degree course. Pharm Educ. 2003;3(1):35-52.

18. Beatty SJ, Kelley KA, Metzger AH, et al. Team-based learning in therapeutics workshop sessions. Am J Pharm Educ. 2009;73 (6):1-7 Article 100 .

19. Redwanski J. Incorporating team-based learning in a drug information course covering tertiary literature. Curr Pharm Teach Learn. 2012;4(3):202-206.

20. Kolleru S, Roesch DM, Aktar de la Fuente A. A multiinstructor, team-based, active-learning exercise to integrate basic and clinical sciences content. Am J Pharm Educ 2012;76(2): Article 33.

21. Hasan S. Teaching ethics to pharmacy students using a teambased learning approach. Pharm Educ. 2011;11(1):99-106.

22. Anwar K, Shaikh AA, Dash NR, et al. Comparing the efficacy of team based learning strategies in a problem based learning curriculum. APMIS. 2012;120(9):718-723.

23. Chung E, Rhee JA, Baik YH, et al. The effect of team-based learning in medical ethics education. Med Teach.. 2009;31(11): 1013-1017.

24. Koles P, Nelson S, Stolfi A, et al. Active learning in year 2 pathology curriculum. Med Educ. 2005;39(10):1045-1055. 
856 25. Koles P, Stolfi A, Borges N, et al. The impact of team-based 857 randomized study. Med Educ. 1999;33(2):106-113.

28. Verhoeven BH, Verwijnen GM, Scherpbier AJ, et al. An analysis of progress test results of PBL and non-PBL students. Med Teach. 1998;20(4):310-316.

29. Addo-Atuah J. Changing student preferences for learning and evaluation: a call for faculty development in active learning and evaluation techniques. Pharm Educ. 2010;10(2):173.
30. Nieder GL, Parmelee DX, Stolfi A, et al. Team-based learning in a medical gross anatomy and embryology course. Clin Anat. 2005;18(1):56-63.

31. Zgheib NK, Simaan JA, Sabra R. Using team-based learning to teach pharmacology to second year medical students improves student performance. Med Teach. 2010;32(2):130-135.

32. Schmidt HG, Rotgans JI. Yew EHJ. The process of problembased learning: what works and why. Med Educ. 2011;45(8): 792-806.

33. Taylor KMG, Harding G. The pharmacy degree: the student experience of professional training. Pharm Educ. 2007;7(1): 83-88.
34. Albanese M. Problem-based learning: why curricula are likely to show little effect on knowledge and clinical skills. Med Educ. 2000;34(9):729-738. 